\section{Heritability and Genetic Variance Estimates for Fruit Weight in Watermelon}

\author{
Gabriele Gusmini and Todd C. Wehner ${ }^{1}$ \\ Department of Horticultural Science, North Carolina State University, \\ Box 7609, Raleigh, NC 27695-7609
}

Additional index words. inheritance, yield, Citrullus lanatus

\begin{abstract}
Fruit weight in the cultivated watermelon [Citrullus lanatus (Thunb.) Matsum. \& Nakai var. lanatus] ranges from $1 \mathrm{~kg}$ to over $100 \mathrm{~kg}$. In recent years, preference of consumers has shifted toward fruit of smaller sizes than the large sizes traditionally used for parties and picnics. This has produced increased interest in the genetics of fruit weight, especially among watermelon breeders. The objectives of this study were to determine the inheritance of fruit weight. Six adapted cultivars having very large or very small fruit weight were crossed in a half diallel. Field trials were conducted at two locations in North Carolina (Clinton and Kinston). Large-fruited parents had higher phenotypic variance than small-fruited parents. Environmental variance was higher than genetic variance (mean, 7.58 and 3.82, respectively) at Kinston, NC. At Clinton, NC, genetic and environmental variances were similar (mean, 9.45 and 8.99 , respectively) for $67 \%$ of the families. Narrow- and broad-sense heritability estimates were low to intermediate (mean, 0.59 and 0.41 , respectively). A high number of effective factors (mean, 5.4) was found to influence fruit weight in watermelon. Watermelon breeders should use quantitative methods such as recurrent selection for population improvement to change fruit weight in the development of new cultivars.
\end{abstract}

The fruit of the cultivated watermelon [Citrullus lanatus (Thunb.) Matsum. \& Nakai var. lanatus] vary in weight from $1 \mathrm{~kg}$ to over $100 \mathrm{~kg}$ depending on cultivar and environmental conditions. In the United States, commercial fruit are usually classified into five categories: icebox (less than $5.5 \mathrm{~kg}$ ), small or pee wee $(5.5-8.0 \mathrm{~kg})$, medium $(8.1-11.0 \mathrm{~kg})$, large (11.1-14.5 kg), and giant (greater than $14.5 \mathrm{~kg}$ ) (Maynard, 2001). One of the smallest-fruited watermelon cultivars is 'New Hampshire Midget', released by the University of New Hampshire in 1951. This cultivar has fruit with oval shape, thin rind, gray skin, red flesh, and black seeds and produces very early fruit of icebox size (Wehner, 2002). Fruit of smaller size (less than $0.5 \mathrm{~kg}$ ) can be found in wild relatives of the cultivated watermelon such as $C$. colocynthis, which are typically used in Africa as animal forage.

In recent years, consumers in the United States have been increasingly interested in seedless watermelons weighing 7 to $10 \mathrm{~kg}$. In 2003, a new fruit size category was introduced under the name of mini watermelon. Cultivars produce fruit that are round, have a thin rind, and weigh between 1.5 and $4.0 \mathrm{~kg}$. Leading cultivars among those currently available are 'Petite Perfection', 'Precious

Received for publication 2 June 2006. Accepted for publication 1 May 2007.

We thank Ms. Tammy L. Ellington and Ms. Meri Reeber for their assistance with plant production in the field and greenhouse.

${ }^{1}$ To whom reprint requests should be addressed; e-mail Todd_Wehner@NCSU.edu.
Petite' (Syngenta Seeds-Rogers Brand, Boise, ID), and cultivars of the Bambino trademark (Seminis Vegetable Seeds, St. Louis) (Schultheis et al., 2005). Although mini watermelons occupy a small portion of the market, their introduction and appreciation by consumers has increased the interest of with reduced fruit size.

Fruit weight in watermelon production is an important descriptor of fruit type, although it can also be considered a yield component. Yield is defined as the total weight per unit area. In the United States, growers expect to harvest at least "one load of fruit" per acre of land, corresponding to $50.5 \mathrm{Mg} \cdot \mathrm{ha}^{-1}$ (metric ton $\cdot \mathrm{ha}^{-1}$ ) of marketable fruit (Maynard, 2001). Marketable fruit must be free of defects and fall into the weight classes most desired by consumers. Currently, smaller sizes are preferred over the traditional large watermelon as a dessert for parties and picnics.

The genetics of watermelon have been studied widely, and many genes have been described (Cucurbit Gene List Committee, 1979, 1982; Henderson, 1991, 1992; Rhodes and Dane, 1999). However, single genes or quantitative trait loci have not been identified for watermelon fruit weight. In two preliminary studies on the inheritance of fruit weight, significant additive, dominance, and epistatic effects were reported, dominance and dominance-by-dominance being the largest gene effects (Brar and Nandpuri, 1974; Sharma and Choudhury, 1988).

Several methods of estimating heritability and predicting selection response are available. Primarily, these methods partition the watermelon breeders in developing cultivars total variance into genetic and environmental variances, and the genetic variance into additive and dominance components and interallelic interaction effects, whenever the population structure and composition allows (Holland et al., 2003; Nyquist, 1991). Among others, a design based on the measure of variance from six generations $\left(\mathrm{P}_{\mathrm{a}}, \mathrm{P}_{\mathrm{b}}, \mathrm{F}_{1}, \mathrm{~F}_{2}\right.$, $\mathrm{BC}_{1} \mathrm{P}_{\mathrm{a}}$, and $\mathrm{BC}_{1} \mathrm{P}_{\mathrm{b}}$ ) can be used to estimate environmental, genetic, and additive variances. The variance of the $F_{2}$ provides an estimate of phenotypic variance, whereas the mean variance of the nonsegregating generations $\left(\mathrm{P}_{\mathrm{a}}, \mathrm{P}_{\mathrm{b}}\right.$, and $\left.\mathrm{F}_{1}\right)$ gives an estimate of environmental effects (Wright, 1968). The additive variance is derived by subtracting the variances of the backcrosses from twice the phenotypic $\left(\mathrm{F}_{2}\right)$ variance as an extension of the single locus model under the hypothesis of absence of linkage and genetic-byenvironment interactions (Warner, 1952). The broad- and narrow-sense heritability and the predicted gain from selection can then be calculated from the available estimates of genetic, additive, and phenotypic variances.

The objective of this experiment was to estimate the heritability and genetic variances of fruit weight in watermelon using a set of crosses of giant by icebox-type inbreds using measures of variances of six generations $\left(\mathrm{P}_{\mathrm{a}}, \mathrm{P}_{\mathrm{b}}, \mathrm{F}_{1}, \mathrm{~F}_{2}, \mathrm{BC}_{1} \mathrm{P}_{\mathrm{a}}\right.$, and $\left.\mathrm{BC}_{1} \mathrm{P}_{\mathrm{b}}\right)$ for each cross. The information would be of great help to watermelon breeders in choosing appropriate breeding methods aimed at modifying fruit weight of their cultivars. A confirmation of the quantitative nature of this trait would indicate the need for techniques such as recurrent selection in improvement of populations specifically dedicated to a weight class of interest.

\section{Materials and Methods}

In the experiment, we used nine families developed from nine crosses of Citrullus lanatus var. lanatus inbred cultivars. Each of three cultivars having giant fruit-'Weeks NC Giant', 'Cobbs Gem', and 'Carolina Cross \#183' - was crossed with three cultivars having small fruit-'Petite Sweet', 'Minilee', and 'NH Midget' (Fig. 1). For each family, we developed six related generations $\left(\mathrm{P}_{\mathrm{a}} \mathrm{S}_{1}, \mathrm{P}_{\mathrm{b}} \mathrm{S}_{1}, \mathrm{~F}_{1}, \mathrm{~F}_{2}, \mathrm{BC}_{1} \mathrm{P}_{\mathrm{a}}\right.$, and $\mathrm{BC}_{1} \mathrm{P}_{\mathrm{b}}$ ) in the greenhouse at North Carolina State University in Raleigh, NC.

Seeds from all six generations of each family were sown in 72-square-cell plug polyethylene flats in the greenhouse at North Carolina State University in Raleigh, NC. A soilless growing medium was used (Canadian sphagnum peatmoss, perlite, vermiculite, processed pine bark). The medium was moistened to capacity after seeding and held in the greenhouse $\left(25\right.$ to $\left.30{ }^{\circ} \mathrm{C}\right)$ until seedlings had fully emerged. Transplants were moved to an open coldframe at the field site for acclimation for 2 weeks before transplanting.

The field test was run in the summer of 2004 at two locations: the Horticultural 
Crops Research Station in Clinton and the Cunningham Research Station in Kinston, NC. At each location, all six generations of the same family were planted. Single plants were transplanted into rows in the following order and number: $\mathrm{P}_{\mathrm{a}} \mathrm{S}_{1},(10), \mathrm{P}_{\mathrm{b}} \mathrm{S}_{1}$ (10), $\mathrm{BC}_{1} \mathrm{P}_{\mathrm{a}},(30) \mathrm{BC}_{1} \mathrm{P}_{\mathrm{b}}(30), \mathrm{F}_{1}(20)$, and $\mathrm{F}_{2}$ (100) at Clinton and $\mathrm{P}_{\mathrm{a}} \mathrm{S}_{1}(10), \mathrm{P}_{\mathrm{b}} \mathrm{S}_{1}$ (10), $\mathrm{F}_{1}(20), \mathrm{BC}_{1} \mathrm{P}_{\mathrm{a}}(30), \mathrm{BC}_{1} \mathrm{P}_{\mathrm{b}}(30)$, and $\mathrm{F}_{2}(110)$ at Kinston. At Clinton, each field was 0.4 ha with eight rows $60 \mathrm{~m}$ long and each family occupied four rows. At Kinston, each field was 0.4 ha with six rows $85 \mathrm{~m}$ long and each family occupied three rows. The fields had raised, shaped beds (rows) on 3.1-m centers with single hills $1.2 \mathrm{~m}$ apart.

Field rows were made up with drip tubing and covered with black polyethylene mulch. The experiment was conducted using horticultural practices recommended by the North Carolina Extension Service (Sanders, 2004). Soil type was an Orangeburg loamy sand at Clinton and a Norfolk sandy loam at Kinston.

Each plant was manually trained each week in a spiral by turning all the vines in a clockwise circle around the crown until $\approx 70 \%$ of the plants in the field had set fruit (Fig. 2). Plant training allowed accurate identification of each fruit and avoided duplication or misclassification of plants, generations, and families. It is possible that environmental variation resulting from light intensity on the canopy may have been increased by the practice of turning the vines in a spiral. However, we opted for increased precision in assigning fruit to plants, thus reducing experimental error. In future experiments, other researchers may need to identify a method that allows easy tracing of the vines without turning them in a spiral.

The fields were harvested when more than $90 \%$ of the fruit were ripe. Fruit were determined to be ripe by looking for a dried tendril nearest the fruit, a light-colored ground spot, and a dull sound of the fruit when thumped (hit with a flat hand on the side of the fruit) (Maynard, 2001). One fruit was harvested from each plant. Most of the plants had only one fruit as is common for watermelon. Furthermore, we have never found more than one fruit per plant that was fully mature, possibly as a result of our early harvest dates. Weights were recorded by approximation to the nearest pound and then converted to kilograms before statistical analysis.

The fruit of the giant-fruited parents in the family 'Weeks NC Giant' $x$ 'Minilee' at Kinston were smaller than expected, possibly as a result of problems of water drainage in the field during fruit development. Therefore, the data from those families were presented in the tables but were considered missing data for the calculation of means by location and overall means.

We tested the $\mathrm{F}_{2}$ data for homogeneity of variances using Bartlett's method (Ostle and Malone, 1988; Steel et al., 1997). Because the variances were heterogeneous, we analyzed the data by family and location. Phenotypic $(P)$, environmental $(E)$, genotypic $(G)$, and additive (A) effects were estimated from

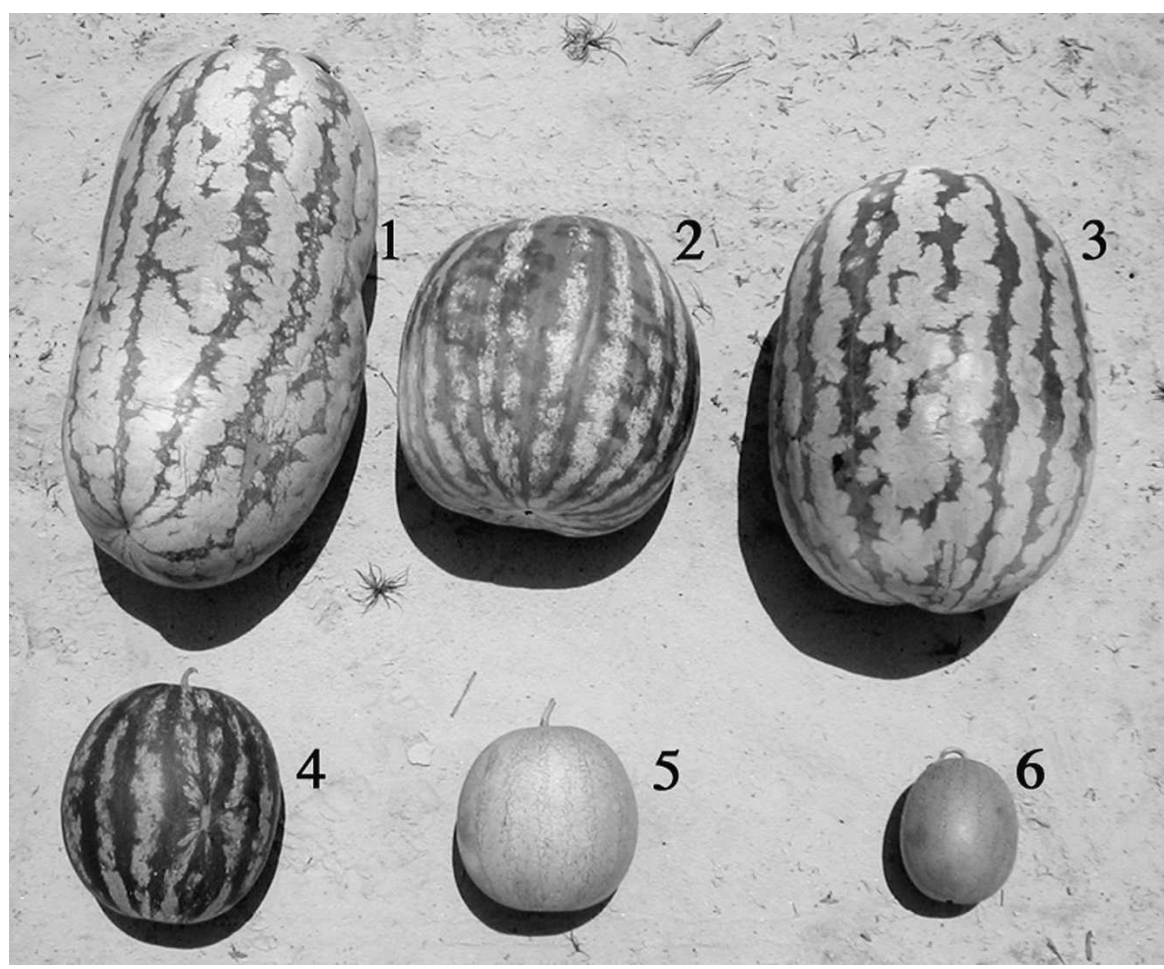

Fig. 1. Each of the three cultivars with giant fruit 'Carolina Cross \#183' (1), 'Cobbs Gem' (2), and 'Weeks NC Giant' (3) was crossed with the three cultivars with small fruit 'Petite Sweet' (4), 'Minilee' (5), and 'NH Midget' (6) to estimate the variance components and heritability of fruit weight in watermelon.

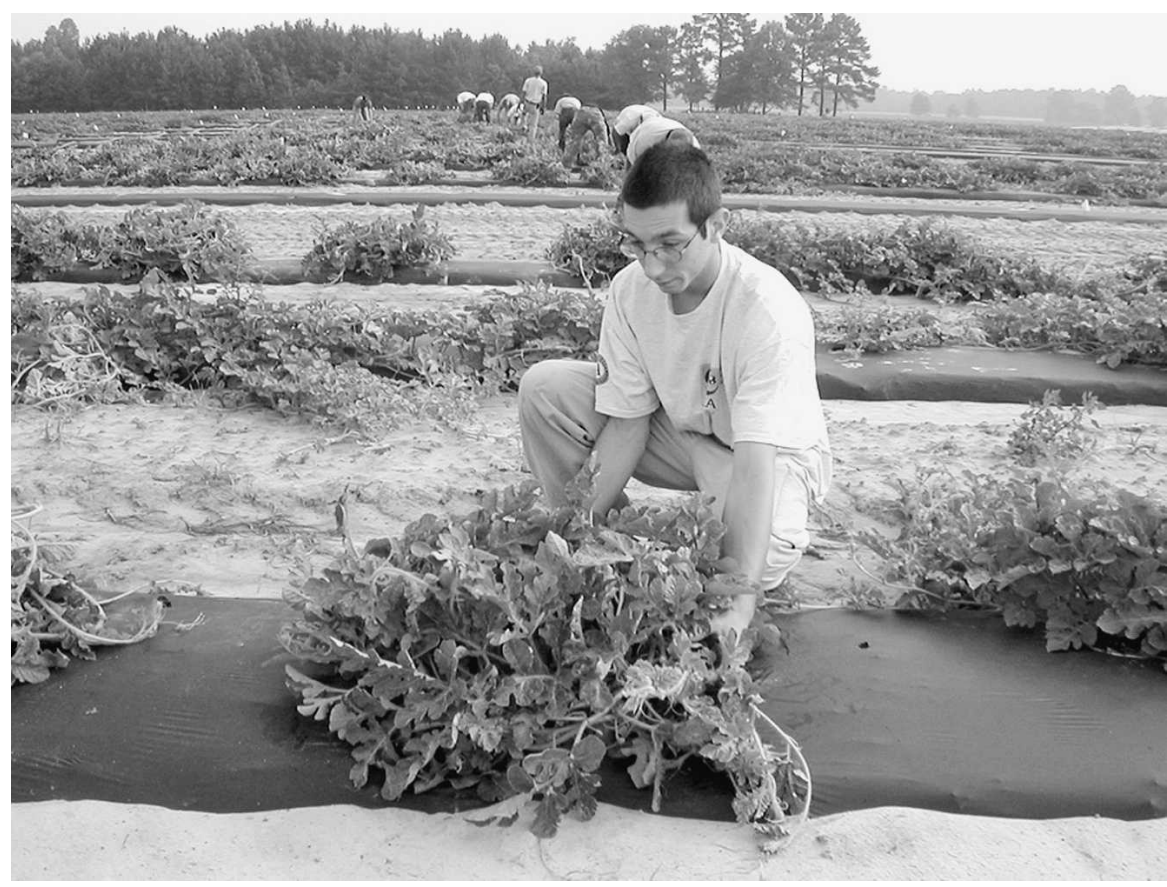

Fig. 2. To keep families, generations, and plants separate for data collection, each plant was manually trained each week into a spiral shape by turning all the vines in a clockwise circle around the crown until $\approx 70 \%$ of the plants in the field set fruit.

generation variances as follows (Warner, 1952; Wright, 1968):

$$
\begin{aligned}
& \sigma^{2}(P)=\sigma^{2}\left(F_{2}\right) \\
& \sigma^{2}(E)=\frac{\sigma^{2}\left(P_{a}\right)+\sigma^{2}\left(P_{b}\right)+\left[2 \times \sigma^{2}\left(F_{1}\right)\right]}{4}
\end{aligned}
$$

$$
\begin{aligned}
\sigma^{2}(G)= & \sigma^{2}(P)-\sigma^{2}(E) \\
\sigma^{2}(A)= & {\left[2 \times \sigma^{2}\left(F_{2}\right)\right] } \\
& -\left[\sigma^{2}\left(B C_{1} P_{a}\right)+\sigma^{2}\left(B C_{1} P_{a}\right)\right]
\end{aligned}
$$

Negative estimates for genetic variances are possible with the experiment design adopted. 
Negative estimates should be considered equal to zero (Robinson et al., 1955) but should be reported "in order to contribute to the accumulation of knowledge, which may, in the future, be properly interpreted" (Dudley and Moll, 1969). We considered negative estimates equal to zero for the calculation of the mean estimates over families or locations. When a negative estimate was derived from another negative value (narrow-sense heritability and gain from selection calculated from additive variance), it was considered close to zero and omitted.

The number of effective factors, an estimate of the genetic factors determining a quantitative trait (Mendelian genes or quantitative trait loci), was estimated using the following five methods (Lande, 1981; Mather and Jinks, 1982; Wright, 1968): were higher at Clinton than at Kinston (12.2 versus $8.7 \mathrm{~kg}$, respectively). Furthermore, the fruit weight of the parental inbred lines was closer to the expected weights at Clinton. Nevertheless, we were interested in variance estimates and not in mean performance across environments, so we presented the data from both locations. The measured variances were not homogeneous across locations and families based on Bartlett's test (Ostle and Malone, 1988; Steel et al., 1997). Therefore, the data were analyzed separately by location and family.

Parental variance of giant-fruited cultivars was larger than that of small-fruited ones (13.15 versus 1.16, respectively) at both locations (Table 1). The giant-fruited cultivars also had large differences in variance
Lande's method I: $\frac{\left[\mu\left(P_{b}\right)-\mu\left(P_{a}\right)\right]^{2}}{8 \times\left\{\sigma^{2}\left(F_{2}\right)-\frac{\sigma^{2}\left(P_{a}\right)+\sigma^{2}\left(P_{b}\right)+\left[2 \times \sigma^{2}\left(F_{1}\right)\right]}{4}\right\}}$

Lande's method II: $\frac{\left[\mu\left(P_{b}\right)-\mu\left(P_{a}\right)\right]^{2}}{8 \times\left\{\left[2 \times \sigma^{2}\left(F_{2}\right)\right]-\left[\sigma^{2}\left(B C_{1} P_{a}\right)+\sigma^{2}\left(B C_{1} P_{a}\right)\right]\right\}}$

Lande's method III: $\frac{\left[\mu\left(P_{b}\right)-\mu\left(P_{a}\right)\right]^{2}}{\left\{8 \times\left[\sigma^{2}\left(B C_{1} P_{a}\right)+\sigma^{2}\left(B C_{1} P_{a}\right)-\sigma^{2}\left(F_{1}\right)\right]\right\}-\frac{\left[\sigma^{2}\left(P_{a}\right)+\sigma^{2}\left(P_{b}\right)\right]}{2}}$

Mather's method: $\frac{\frac{\left[\mu\left(P_{b}\right)-\mu\left(P_{a}\right)\right]^{2}}{2}}{\left[2 \times \sigma^{2}\left(F_{2}\right)\right]-\left[\sigma^{2}\left(B C_{1} P_{a}\right)+\sigma^{2}\left(B C_{1} P_{a}\right)\right]}$

Wright's method: $\frac{\left[\mu\left(P_{b}\right)-\mu\left(P_{a}\right)\right]^{2} \times\left\{1.5-\left[2 \times \frac{\mu\left(F_{1}\right)-\mu\left(P_{a}\right)}{\mu\left(P_{b}\right)-\mu\left(P_{a}\right)} \times\left(1-\frac{\mu\left(F_{1}\right)-\mu\left(P_{a}\right)}{\mu\left(P_{b}\right)-\mu\left(P_{a}\right)}\right)\right]\right\}}{8 \times\left\{\sigma^{2}\left(F_{2}\right)-\frac{\sigma^{2}\left(P_{a}\right)+\sigma^{2}\left(P_{b}\right)+\left[2 \times \sigma^{2}\left(F_{1}\right)\right]}{4}\right\}}$ among families for the same cultivar. For example, different families where 'Carolina Cross \#183' (giant-fruited) was used as one parent had a variance of $29.83,16.73$, and 9.16 at Clinton or 23.23, 6.34, and 8.29 at Kinston. On the other hand, the small-fruited parents had similar variance among families and locations (1.12 at Clinton versus 1.16 at Kinston). $F_{2}$ variance (Table 1) had a twofold range within location, thus indicating a great phenotypic variability in our experiment. Consequently, the experiment well magnified differences among fruit within family increasing the precision of our estimates. Variance of the backcrosses (Table 1) had a threefold variation within location. However, backcross variance was consistent among location and within family, thus indicating high accuracy of the estimates of additive effects.

Overall, the environmental variance was larger than the genetic variance in the majority of the families at both locations $(8.52$ versus 6.41, respectively) (Table 2). However, genotype had similar or larger effect than environment for $78 \%$ of the families at Clinton. Thus, a uniform environment (Clinton) was more favorable to control environmental variation than testing at multiple locations.

Additive genetic effects were estimated, but a comparison with dominance effects was not possible. With our experiment design, dominance variance could be estimated by subtraction of genetic and additive variances from the phenotypic variance, but such an indirect estimate would not be precise. In future studies, specific crosses for measuring dominance effects for fruit weight through a North Carolina Design III (Hallauer and Miranda, 1988) should be developed. In comparison with all genetic effects (phenotypic, environmental, genetics, additive),
The possible gain from selection per cycle was predicted as $h_{n}^{2} \times \sqrt{\sigma^{2}(P)}$ multiplied by the selection differential in standard deviation units $\mathrm{k}$ for selection intensities of $5 \%$, $10 \%$, or $20 \%$ (Hallauer and Miranda, 1988). The statistical analysis was performed using the SAS-STAT statistical package (SAS Institute, Cary, NC).

\section{Results and Discussion}

In our experiments, watermelon fruit weight was a quantitative trait with normal distribution of the $\mathrm{F}_{2}$ data for all the families tested (Fig. 3). As a result of the large and continuous variation of the data, it was not possible to identify discrete classes of weight to analyze the data using a Mendelian model.

The field at Clinton had fewer problems with standing water during fruit development than at Kinston, providing a better environment for growth for those families. Overall, the crop at Clinton appeared more vigorous and uniform than at Kinston, although cultural practices were similar, and there was no problem with biotic or abiotic diseases at either location. The overall mean weights

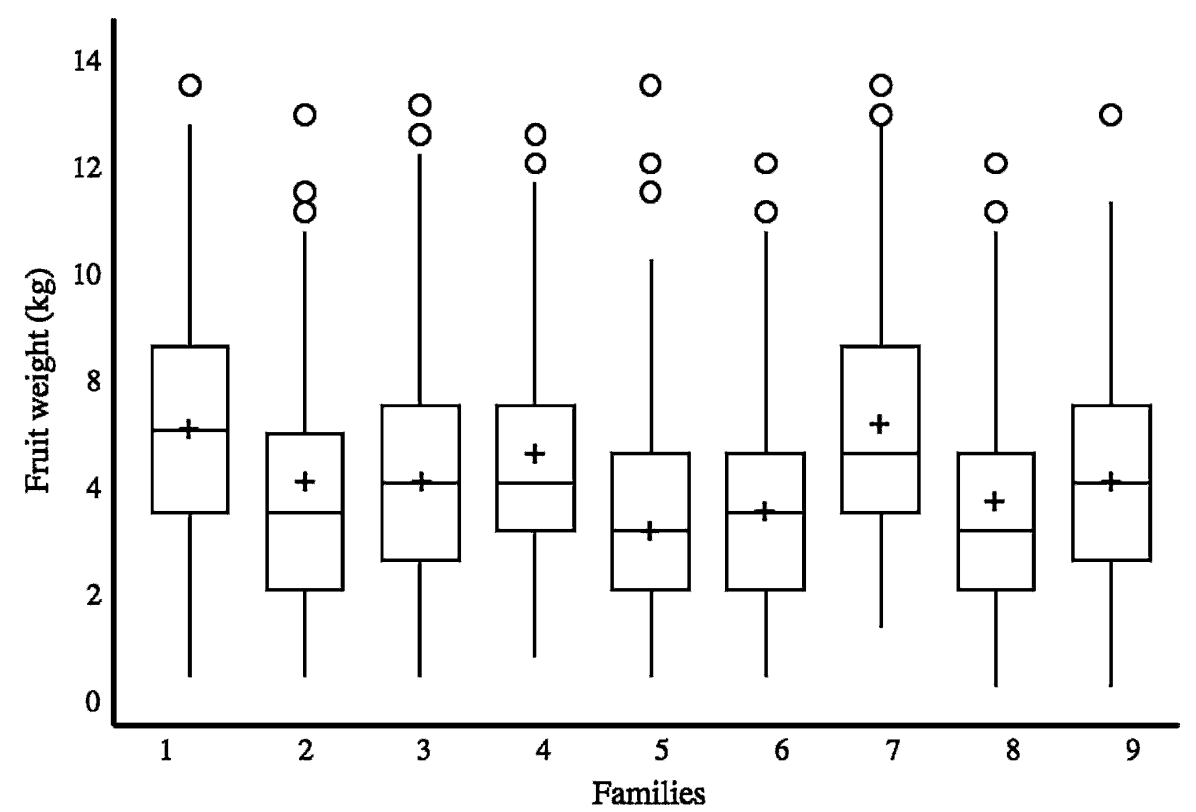

Fig. 3. Box-plots showing the distribution of $F_{2}$ data for the nine families tested to determine heritability and genetic variances for fruit weight in watermelon. Families: 1 = 'Carolina Cross \#183' $\times$ 'Petite Sweet'; 2 = 'Carolina Cross \#183' $\times$ 'Minilee'; 3 = 'Carolina Cross \#183' $\times$ 'NH Midget'; 4 = 'Cobbs Gem' $\times$ 'Petite Sweet'; 5 = 'Cobbs Gem' $\times$ 'Minilee'; 6 = 'Cobbs Gem' $\times$ 'NH Midget'; 7 = 'Weeks NC Giant' $\times$ 'Petite Sweet'; 8 = 'Weeks NC Giant' $\times$ 'Minilee'; $9=$ 'Weeks NC Giant' $\times$ 'NH Midget'. 
Table 1. Phenotypic variances by generation for the watermelon families tested for fruit weight in 2004 at Clinton and Kinston, NC. ${ }^{\mathrm{z}}$

\begin{tabular}{|c|c|c|c|c|c|c|}
\hline Pedigree & $\sigma^{2}\left(\mathrm{P}_{\mathrm{a}}\right)$ & $\sigma^{2}\left(\mathrm{P}_{\mathrm{b}}\right)$ & $\sigma^{2}\left(\mathrm{~F}_{1}\right)$ & $\sigma^{2}\left(\mathrm{~F}_{2}\right)$ & $\sigma^{2}\left(\mathrm{BC}_{1} \mathrm{P}_{\mathrm{a}}\right)$ & $\sigma^{2}\left(\mathrm{BC}_{1} \mathrm{P}_{\mathrm{b}}\right)$ \\
\hline \multicolumn{7}{|l|}{ Clinton } \\
\hline Carolina Cross \#183 $\times$ Petite Sweet & 29.83 & 2.59 & 10.45 & 28.62 & 12.81 & 6.60 \\
\hline Carolina Cross $\# 183 \times$ Minilee & 16.73 & 0.07 & 12.07 & 22.89 & 37.14 & 7.30 \\
\hline Carolina Cross $\# 183 \times \mathrm{NH}$ Midget & 9.16 & 1.56 & 6.57 & 12.80 & 17.75 & 2.70 \\
\hline Cobbs Gem $\times$ Petite Sweet & 16.95 & 3.15 & 31.64 & 23.52 & 16.30 & 11.25 \\
\hline Cobbs Gem $\times$ Minilee & 5.84 & 0.38 & 5.67 & 11.22 & 36.98 & 7.45 \\
\hline Cobbs Gem $\times$ NH Midget & 35.39 & 0.10 & 4.41 & 13.09 & 10.12 & 5.72 \\
\hline Weeks NC Giant $\times$ Petite Sweet & 18.72 & 1.35 & 11.21 & 24.32 & 21.85 & 8.34 \\
\hline Weeks NC Giant $\times$ Minilee & 4.32 & 0.74 & 5.11 & 17.86 & 11.17 & 16.73 \\
\hline Weeks NC Giant $\times$ NH Midget & 9.63 & 0.16 & 4.66 & 11.70 & 14.07 & 3.43 \\
\hline Mean & 16.29 & 1.12 & 10.20 & 18.45 & 19.80 & 7.72 \\
\hline \multicolumn{7}{|l|}{ Kinston } \\
\hline Carolina Cross \#183 $\times$ Petite Sweet & 23.23 & 3.57 & 8.21 & 15.27 & 8.25 & 9.82 \\
\hline Carolina Cross $\# 183 \times$ Minilee & 6.34 & 0.62 & 14.49 & 14.24 & 28.31 & 8.10 \\
\hline Carolina Cross $\# 183 \times$ NH Midget & 8.29 & 0.05 & 8.12 & 10.62 & 13.95 & 2.58 \\
\hline Cobbs Gem $\times$ Petite Sweet & 2.44 & 2.29 & 11.22 & 13.68 & 9.32 & 10.58 \\
\hline Cobbs Gem $\times$ Minilee & 6.70 & 0.29 & 8.41 & 9.13 & 3.27 & 17.86 \\
\hline Cobbs Gem $\times$ NH Midget & 9.31 & 0.14 & 5.31 & 7.15 & 7.93 & 2.73 \\
\hline Weeks NC Giant $\times$ Petite Sweet & 22.08 & 2.52 & 12.01 & 14.63 & 17.02 & 7.03 \\
\hline Weeks NC Giant $\times$ Minilee & 24.96 & 0.69 & 12.79 & 9.17 & 6.40 & 18.29 \\
\hline Weeks NC Giant $\times$ NH Midget & 1.65 & 0.05 & 8.70 & 6.49 & 22.77 & 2.69 \\
\hline $\operatorname{Mean}^{y}$ & 10.01 & 1.19 & 9.56 & 11.40 & 13.85 & 7.67 \\
\hline Overall mean & 13.15 & 1.16 & 9.88 & 14.93 & 16.83 & 7.70 \\
\hline
\end{tabular}

${ }^{\mathrm{z}}$ Data are single-fruit weights $(\mathrm{kg})$ from nine families of giant- by mini-fruited cultivars of Citrullus lanatus var. lanatus.

${ }^{\mathrm{y}}$ Not including Weeks NC Giant $\times$ Minilee.

Table 2. Variance and heritability estimates for the watermelon families tested for fruit weight in 2004 at Clinton and Kinston, NC. ${ }^{z}$

\begin{tabular}{|c|c|c|c|c|c|c|}
\hline Pedigree & $\sigma^{2}(\mathrm{P})^{\mathrm{y}}$ & $\sigma^{2}(E)^{x}$ & $\sigma^{2}(\mathrm{G})^{\mathrm{w}}$ & $\sigma^{2}(\mathrm{~A})^{\mathrm{v}}$ & $\mathrm{H}^{\mathrm{u}}$ & $h_{n}^{2}{ }^{t}$ \\
\hline \multicolumn{7}{|l|}{ Clinton } \\
\hline Carolina Cross $\# 183 \times$ Petite Sweet & 28.62 & 13.33 & 15.29 & 37.83 & 0.53 & 1.32 \\
\hline Carolina Cross $\# 183 \times$ Minilee & 22.89 & 10.24 & 12.65 & 1.33 & 0.55 & 0.06 \\
\hline Carolina Cross $\# 183 \times$ NH Midget & 12.80 & 5.97 & 6.83 & 5.15 & 0.53 & 0.40 \\
\hline Cobbs Gem $\times$ Petite Sweet & 23.52 & 20.84 & 2.68 & 19.50 & 0.11 & 0.83 \\
\hline Cobbs Gem $\times$ Minilee & 11.22 & 4.39 & 6.83 & -21.99 & 0.61 & 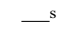 \\
\hline Cobbs Gem $\times$ NH Midget & 13.09 & 11.08 & 2.01 & 10.33 & 0.15 & 0.79 \\
\hline Weeks NC Giant $\times$ Petite Sweet & 24.32 & 10.62 & 13.70 & 18.46 & 0.56 & 0.76 \\
\hline Weeks NC Giant $\times$ Minilee & 17.86 & 3.82 & 14.04 & 7.82 & 0.79 & 0.44 \\
\hline Weeks NC Giant $\times$ NH Midget & 11.70 & 4.78 & 6.92 & 5.90 & 0.59 & 0.50 \\
\hline Mean & 18.45 & 9.45 & 8.99 & 9.37 & 0.49 & 0.64 \\
\hline \multicolumn{7}{|l|}{ Kinston } \\
\hline Carolina Cross $\# 183 \times$ Petite Sweet & 15.27 & 10.80 & 4.46 & 12.47 & 0.29 & 0.82 \\
\hline Carolina Cross $\# 183 \times$ Minilee & 14.24 & 8.99 & 5.26 & -7.93 & 0.37 & $\ldots \mathrm{s}$ \\
\hline Carolina Cross $\# 183 \times$ NH Midget & 10.62 & 6.15 & 4.48 & 4.72 & 0.42 & 0.44 \\
\hline Cobbs Gem $\times$ Petite Sweet & 13.68 & 6.79 & 6.88 & 7.45 & 0.50 & 0.55 \\
\hline Cobbs Gem $\times$ Minilee & 9.13 & 5.95 & 3.18 & -2.87 & 0.35 & 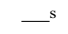 \\
\hline Cobbs Gem $\times$ NH Midget & 7.15 & 5.02 & 2.13 & 3.64 & 0.30 & 0.51 \\
\hline Weeks NC Giant $\times$ Petite Sweet & 14.63 & 12.15 & 2.47 & 5.21 & 0.17 & 0.36 \\
\hline Weeks NC Giant $\times$ Minilee & 9.17 & 12.81 & -3.64 & -6.34 & $\mathrm{c}^{\mathrm{s}} \mathrm{r}(\mathrm{r}) \mathrm{e}$ & $-\mathrm{s}$ \\
\hline Weeks NC Giant $\times$ NH Midget & 6.49 & 4.78 & 1.72 & -12.48 & 0.26 & 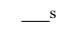 \\
\hline $\operatorname{Mean}^{r}$ & 11.40 & 7.58 & 3.82 & 1.28 & 0.33 & 0.54 \\
\hline Overall mean & 14.93 & 8.52 & 6.41 & 5.33 & 0.41 & 0.59 \\
\hline
\end{tabular}

${ }^{2}$ Data are single-fruit weights $(\mathrm{kg})$ from nine families of giant- by mini-fruited cultivars of Citrullus lanatus var. lanatus.

${ }^{\mathrm{y}} \sigma^{2}(\mathrm{P})=$ phenotypic variance $=\sigma^{2}\left(F_{2}\right)$

${ }^{\mathrm{x}} \boldsymbol{\sigma}^{2}(\mathrm{E})=$ environmental variance $=\frac{\sigma^{2}\left(P_{a}\right)+\sigma^{2}\left(P_{b}\right)+\left[2 \times \sigma^{2}\left(F_{1}\right)\right]}{4}$

${ }^{\mathrm{w}} \sigma^{2}(\mathrm{G})=$ genetic variance $=\sigma^{2}(P)-\sigma^{2}(E)$

${ }^{v} \sigma^{2}(\mathrm{~A})=$ additive variance $=\left[2 \times \sigma^{2}\left(F_{2}\right)\right]-\left[\sigma^{2}\left(B C_{1} P_{a}\right)+\sigma^{2}\left(B C_{1} P_{a}\right)\right]$

" $\mathrm{H}=$ broad-sense heritability.

$\mathrm{h}^{2}{ }_{\mathrm{n}}=$ narrow-sense heritability.

${ }^{\mathrm{s}}$ Negative estimate from a negative estimate of additive variance.

${ }^{\mathrm{r}}$ Not including Weeks NC Giant $\times$ Minilee.

additive genetic components had the largest effect for some families and locations (i.e., 'Carolina Cross \#183' $\times$ 'Petite Sweet' at Clinton) and the smallest for others (i.e., 'Cobbs Gem' × 'Minilee' at Clinton) (Table
2). The relative importance of additive effects among locations and within family also varied greatly ( 0.00 to 37.83$)$, which accounts for the differences in narrow-sense heritability among locations within family.
The narrow-sense heritability was not estimated for those families with negative estimates of additive variance and it should be considered close to zero (Robinson et al., 1955). The broad-sense heritability estimates were higher at Clinton than at Kinston (0.49 versus 0.33 , respectively) (Table 2 ). At Clinton, the broad-sense heritability was intermediate, ranging from 0.53 to 0.61 for $67 \%$ of the families. Similarly, at Kinston, the estimates of broad-sense heritability spanned a narrow range $(0.29$ to 0.50$)$ for $67 \%$ of the families. The estimates varied greatly among locations within family.

The heritability of fruit weight was low to intermediate. The narrow-sense heritability was larger than the broad-sense heritability, although the additive variance estimates were not consistent among families. Therefore, additive components may play an important role in the improvement of fruit weight in watermelon, but further studies that allow direct estimation of additive and dominance effects in multiple and uniform environments may be needed for a correct quantification of these effects.

In our study, two methods (those of Wright and Lande) provided similar estimates of the number of effective factors determining fruit weight. The other three methods provided several negative estimates and were disregarded. The number of effective factors varied from two to seven at Clinton, with the exception of the family 'Cobbs Gem' $\times$ 'NH Midget' that had 25 estimated effective factors and the family 'Weeks NC Giant' $\times$ 'Minilee' that had less than one (Table 3). At Kinston, the range of estimates was larger, but this may depend on the higher variability and lower mean weights recorded at that location. These estimates should be considered only indicative.

The estimated gain from selection depended on family and differed for families even if they shared a common parent (Table 3). For example, data from Clinton predicted a gain in families from 'Carolina Cross \#183' $\times$ 'Petite Sweet' of 9.9 to $14.6 \mathrm{~kg}$ and of 0.4 to $3.0 \mathrm{~kg}$ in the two other crosses. In addition, the predicted gain differed more for some families than others among locations as a result of the high variability for additive variance estimates.

Based on our experiments, it should be possible to change the size of watermelon fruit in a few generations of selection with greater changes under high selection intensities $(4.9 \mathrm{~kg}$ predicted at $\mathrm{k}=5 \%)$. Breeding schemes that would allow high recombination rates may help in combining all the effective factors needed to obtain a desired fruit weight and break unfavorable linkages. Recurrent selection for population improvement should be an effective breeding method, although lower gain per cycle would be obtained as a result of the lower selection intensity (typically $\approx 20 \%$ ). Furthermore, because a relatively small number of effective factors seems to regulate fruit weight, fixation of the trait may be reached in few generations under high selection intensity. 
Table 3. Estimates of number of effective factors and predicted gain from selection under different selection intensities for the watermelon families tested for fruit weight in 2004 at Clinton and Kinston, $\mathrm{NC}{ }^{\mathrm{z}}$

\begin{tabular}{|c|c|c|c|c|c|c|}
\hline \multirow[b]{2}{*}{ Pedigree } & \multicolumn{3}{|c|}{ Effective Factors } & \multicolumn{3}{|c|}{ Gain From Selection $^{\mathrm{y}}$} \\
\hline & Wright $^{x}$ & ${\text { Lande } \mathrm{I}^{\mathrm{w}}}$ & $\overline{\text { Mean }}$ & $\overline{5 \%}$ & $10 \%$ & $20 \%$ \\
\hline \multicolumn{7}{|l|}{ Clinton } \\
\hline Carolina Cross $\# 183 \times$ Petite Sweet & 2.4 & 2.3 & 2.35 & 14.6 & 12.4 & 9.9 \\
\hline Carolina Cross $\# 183 \times$ Minilee & 3.7 & 3.1 & 3.40 & 0.6 & 0.5 & 0.4 \\
\hline Carolina Cross $\# 183 \times \mathrm{NH}$ Midget & 7.0 & 7.0 & 7.00 & 3.0 & 2.5 & 2.0 \\
\hline Cobbs Gem $\times$ Petite Sweet & 5.3 & 5.3 & 5.30 & 8.3 & 7.1 & 5.6 \\
\hline Cobbs Gem $\times$ Minilee & 3.0 & 2.9 & 2.95 & $-^{\mathrm{v}}$ & $-^{\mathrm{v}}$ & $\square^{v}$ \\
\hline Cobbs Gem $\times$ NH Midget & 26.5 & 23.5 & 25.00 & 5.9 & 5.0 & 4.0 \\
\hline Weeks NC Giant $\times$ Petite Sweet & 2.7 & 2.7 & 2.70 & 7.7 & 6.6 & 5.2 \\
\hline Weeks NC Giant $\times$ Minilee & 0.8 & 0.3 & 0.55 & 3.8 & 3.3 & 2.6 \\
\hline Weeks NC Giant $\times$ NH Midget & 5.7 & 5.6 & 5.65 & 3.6 & 3.0 & 2.4 \\
\hline Mean & 6.3 & 5.9 & 6.1 & 5.9 & 5.1 & 4.0 \\
\hline \multicolumn{7}{|l|}{ Kinston } \\
\hline Carolina Cross $\# 183 \times$ Petite Sweet & 4.2 & 4.2 & 4.20 & 6.6 & 5.6 & 4.5 \\
\hline Carolina Cross \#183 $\times$ Minilee & 0.6 & 0.6 & 0.60 & $-^{\mathrm{v}}$ & $\mathrm{C}^{\mathrm{v}}$ & $-v$ \\
\hline Carolina Cross $\# 183 \times \mathrm{NH}$ Midget & 9.7 & 9.6 & 9.65 & 3.0 & 2.5 & 2.0 \\
\hline Cobbs Gem $\times$ Petite Sweet & 0.6 & 0.6 & 0.60 & 4.2 & 3.5 & 2.8 \\
\hline Cobbs Gem $\times$ Minilee & 0.4 & 0.0 & 0.20 & $-\mathrm{v}$ & $-\mathrm{v}$ & $一^{v}$ \\
\hline Cobbs Gem $\times$ NH Midget & 3.4 & 2.9 & 3.15 & 2.8 & 2.4 & 1.9 \\
\hline Weeks NC Giant $\times$ Petite Sweet & 7.7 & 7.6 & 7.65 & 2.8 & 2.4 & 1.9 \\
\hline Weeks NC Giant $\times$ Minilee & -4.1 & -4.0 & -4.05 & $-\mathrm{v}$ & $-\mathrm{v}$ & $-v$ \\
\hline Weeks NC Giant $\times$ NH Midget & 11.6 & 10.7 & 11.15 & $-^{\mathrm{v}}$ & $-^{\mathrm{v}}$ & $-\mathrm{r}$ \\
\hline Mean $^{\mathrm{u}}$ & 4.8 & 4.5 & 4.7 & 3.9 & 3.3 & 2.6 \\
\hline Overall mean & 5.6 & 5.2 & 5.4 & 4.9 & 4.2 & 3.3 \\
\hline
\end{tabular}

${ }^{\mathrm{z}}$ Data are single-fruit weights $(\mathrm{kg})$ from nine families of giant- by mini-fruited cultivars of Citrullus lanatus var. lanatus.

$$
\begin{aligned}
& \frac{\left[\mu\left(P_{b}\right)-\mu\left(P_{a}\right)\right]^{2} \times\left\{1.5-\left[2 \times \frac{\mu\left(F_{1}\right)-\mu\left(P_{a}\right)}{\mu\left(P_{b}\right)-\mu\left(P_{a}\right)} \times\left(1-\frac{\mu\left(F_{1}\right)-\mu\left(P_{a}\right)}{\mu\left(P_{b}\right)-\mu\left(P_{a}\right)}\right)\right]\right\}}{8 \times\left\{\sigma^{2}\left(F_{2}\right)-\frac{\sigma^{2}\left(P_{a}\right)+\sigma^{2}\left(P_{b}\right)+\left[2 \times \sigma^{2}\left(F_{1}\right)\right]}{4}\right\}} \\
& \frac{\mathrm{w}-\left[\mu\left(P_{b}\right)-\mu\left(P_{a}\right)\right]^{2}}{8 \times\left\{\sigma^{2}\left(F_{2}\right)-\frac{\sigma^{2}\left(P_{a}\right)+\sigma^{2}\left(P_{b}\right)+\left[2 \times \sigma^{2}\left(F_{1}\right)\right]}{4}\right\}}
\end{aligned}
$$

vNot including Weeks NC Giant $\times$ Minilee.

"Negative estimate from a negative estimate of additive variance.
Recurrent selection programs in watermelon would require large intercrossing blocks as a result of the large size of the plants. The environmental variation and the intermediate to low heritability observed for this trait may require progeny testing using self-pollination of the half-sib families and trialing in progeny rows at multiple locations. In addition, it may be easier to introgress desired qualitative traits into breeding lines of desired fruit weight by pedigree or backcross breeding rather than trying to change cultivars.

Our study demonstrated that plant breeders can change fruit weight in watermelon populations using effective selection the fruit weight of otherwise acceptable

Cucurbit Gene List Committee. 1982. Update of cucurbit gene list and nomenclature rules. Cucurbit Genetics Cooperative Report. 5:62-66.

Dudley, J.W. and R.H. Moll. 1969. Interpretation and use of estimates of heritability and genetic variances in plant breeding. Crop Sci. 9:257-262.

Hallauer, A.R. and J.B. Miranda. 1988. Quantitative genetics in maize breeding. Iowa State University Press, Ames, IA.

Henderson, W.R. 1991. Gene list for watermelon. Cucurbit Genetics Cooperative Report. 14: 129-138.

Henderson, W.R. 1992. Corrigenda to 1991 watermelon gene list (CGC 14:129-137). Cucurbit Genetics Cooperative Report. 15:110.

Holland, J.B., W.E. Nyquist, and C.T. CervantesMartinez. 2003. Estimating and interpreting heritability for plant breeding: An update. Plant Breed. Rev. 22:9-113.

Lande, R. 1981. The minimum number of genes contributing to quantitative variation between and within populations. Genetics 99:541-553.

Mather, K. and J.L. Jinks. 1982. Biometrical genetics. The study of continuous variation. Chapman and Hall, London, New York

Maynard, D.N. (ed.). 2001. Watermelons. Characteristics, production, and marketing. ASHS Press, Alexandria, VA.

Nyquist, W.E. 1991. Estimation of heritability and prediction of selection response in plant populations. Crit. Rev. Plant Sci. 10:235-322.

Ostle, B. and L.C. Malone. 1988. Statistics in research. Iowa State University Press, Ames, IA

Rhodes, B. and F. Dane. 1999. Gene list for watermelon. Cucurbit Genetics Cooperative Report. 22:61-77.

Robinson, H.F., R.E. Comstock, and P.H. Harvey. 1955. Genetic variances in open pollinated varieties of corn. Genetics 40:45-60.

Sanders, D.C. (ed.). 2004. Vegetable crop guidelines for the Southeastern U.S. 2004-2005. North Carolina Vegetable Growers Association, Raleigh, NC.

Schultheis, J.R., W.B. Thompson, W.R. Jester, and C.B. Taylor. 2005. 2004 Cucurbit cultivar evaluations. Horticultural Research Series. No. 162.88 pp.

methods. However, low heritability, quantitative inheritance, and high environmental variance are important limiting factors that may greatly reduce the realized gain from selection in populations of cultivated watermelon and may require progeny testing rather than single-plant selection methods to be most effective.

\section{Literature Cited}

Brar, J.S. and K.S. Nandpuri. 1974. Inheritance of fruit weight in water-melon [Citrullus lanatus (Thunb.) Mansf.]. Journal of Research, Punjab Agricultural Service. 11:140-144.

Cucurbit Gene List Committee. 1979. New genes for the Cucurbitaceae. Cucurbit Genetics Cooperative Report. 2:49-53.

Sharma, R.R. and B. Choudhury. 1988. Studies on some quantitative characters in watermelon (Citrullus lanatus Thunb. Mansf.). I. Inheritance of earliness and fruit weight. Indian Journal of Horticulture. 45:80-84.

Steel, R.G.D., J.H. Torrie, and D.A. Dickey. 1997. Principles and procedures of statistics: A biometrical approach. WCB/McGraw-Hill, Boston, MA.

Warner, J.N. 1952. A method for estimating heritability. Agron. J. 44:427-430.

Wehner, T.C. 2002. Vegetable cultivar descriptions for North America. List 26-2002. HortScience 37:15-78.

Wright, S. 1968. The genetics of quantitative variability, p. 373-420. In: S. Wright (ed.). Evolution and genetics of populations. University of Chicago Press, Chicago, IL. 